\title{
Embedding tin disulfide nanoparticles in two- dimensional porous carbon nanosheet interlayers for fast-charging lithium-sulfur batteries
}

\author{
$\mathrm{Na} \mathrm{Zhou}^{1 \dagger}$, Wen-Da Dong ${ }^{1 \dagger}$, Yun-Jing Zhang ${ }^{1}$, Di Wang ${ }^{1}$, Liang Wu ${ }^{1}$, Lang Wang ${ }^{1,2}$, Zhi-Yi Hu ${ }^{1,2}$, \\ Jing Liu ${ }^{1}$, Hemdan S. H. Mohamed ${ }^{1,3}, \mathrm{Yu} \mathrm{Li}^{1,2^{*}}, \mathrm{Li}-\mathrm{Hua}$ Chen ${ }^{1}$ and Bao-Lian Su${ }^{1,4^{*}}$
}

\begin{abstract}
Lithium-sulfur (Li-S) batteries have attracted significant attention for their high specific capacity, non-toxic and harmless advantages. However, the shuttle effect limits their development. In this work, small-sized tin disulfide $\left(\mathrm{SnS}_{2}\right)$ nanoparticles are embedded between interlayers of twodimensional porous carbon nanosheets (PCNs), forming a multi-functional nanocomposite $\left(\mathrm{PCN}-\mathrm{SnS}_{2}\right)$ as a cathode carrier for $\mathrm{Li}-\mathrm{S}$ batteries. The graphitized carbon nanosheets improve the overall conductivity of the electrode, and the abundant pores not only facilitate ion transfer and electrolyte permeation, but also buffer the volume change during the charge and discharge process to ensure the integrity of the electrode material. More importantly, the physical confinement of PCN, as well as the strong chemical adsorption and catalytic reaction of small $\mathrm{SnS}_{2}$ nanoparticles, synergistically reduce the shuttle effect of polysulfides. The interaction between a porous layered structure and physical-chemical confinement gives the $\mathrm{PCN}-\mathrm{SnS}_{2}-\mathrm{S}$ electrode high electrochemical performance. Even at a high rate of $2 \mathrm{C}$, a discharge capacity of $650 \mathrm{~mA} \mathrm{~h} \mathrm{~g}^{-1}$ is maintained after 150 cycles, underscoring the positive results of $\mathrm{SnS}_{2}$-based materials for Li-S batteries. The galvanostatic intermittent titration technique results further confirm that the $\mathrm{PCN}-\mathrm{SnS}_{2}-\mathrm{S}$ electrode has a high $\mathrm{Li}^{+}$transmission rate, which reduces the activation barrier and improves the electrochemical reaction kinetics. This work provides strong evidence that reducing the size of $\mathrm{SnS}_{2}$ nanostructures is beneficial for capturing and reacting with polysulfides to alleviate their shuttle effect in Li-S batteries.
\end{abstract}

Keywords: tin disulfide nanoparticles, porous carbon na- nosheets, lithium-sulfur batteries, galvanostatic intermittent titration technique, density functional theory

\section{INTRODUCTION}

With the rapid development of electric vehicles and portable electronic devices, there is an urgent need to develop batteries with high energy densities [1,2]. With the lithium metal as an anode and sulfur or sulfur-containing compounds as a cathode, lithium-sulfur (Li-S) batteries have received significant attention for their theoretically high capacity $\left(1675 \mathrm{~mA} \mathrm{~h} \mathrm{~g}^{-1}\right)$ and energy density (2600 $\mathrm{W} \mathrm{h} \mathrm{kg}^{-1}$ ) [3,4]. Furthermore, the abundance of elemental sulfur in nature, the low manufacturing cost of Li-S batteries, and their non-toxic nature also encourage their development [5]. In these batteries, the lithium in the anode generally loses electrons and becomes lithium ions, while the sulfur in the cathode is first transformed into $\mathrm{Li}_{2} \mathrm{~S}_{8}$ during the discharge. In the first discharge platform, $\mathrm{Li}_{2} \mathrm{~S}_{8}$ transforms into $\mathrm{Li}_{2} \mathrm{~S}_{4}$ through $\mathrm{Li}_{2} \mathrm{~S}_{6}$ at approximately $2.4 \mathrm{~V}$, which contributes $25 \%$ of the battery's theoretical capacity; in the second discharge platform, $\mathrm{Li}_{2} \mathrm{~S}_{4}$ is transformed into $\mathrm{Li}_{2} \mathrm{~S}$ at approximately $2.0 \mathrm{~V}$, which contributes $75 \%$ of the theoretical capacity, while the charging process initiates the opposite process [6,7]. Although Li-S batteries have development advantages, there remain several problems that seriously hinder their development. The shuttle effect, caused by the migration of polysulfides between the anode and cathode, is considered the largest obstacle to

\footnotetext{
${ }^{1}$ State Key Laboratory of Advanced Technology for Materials Synthesis and Processing, Wuhan University of Technology, Wuhan 430070, China

${ }^{2}$ Nanostructure Research Center (NRC), Wuhan University of Technology, Wuhan 430070, China

${ }^{3}$ Physics Department, Faculty of Science, Fayoum University, El Gomhoria Street, 63514 Fayoum, Egypt

${ }^{4}$ Laboratory of Inorganic Materials Chemistry (CMI), University of Namur, 61 rue de Bruxelles, B-5000 Namur, Belgium

${ }^{\dagger}$ These authors contributed equally to this work.

*Corresponding authors (emails: yu.li@whut.edu.cn (Li Y); baoliansu@whut.edu.cn or bao-lian.su@unamur.be (Su BL))
} 
the development of Li-S batteries. This effect leads to the loss of cathode material and capacity decay, and the anode deposition of polysulfides is not conducive to the transmission of electrons and ions. In the discharge process of $\mathrm{Li}_{2} \mathrm{~S}_{8}$ transforming into $\mathrm{Li}_{2} \mathrm{~S}$, the difference in their densities causes volume expansion. Meanwhile, the elemental sulfur and $\mathrm{Li}_{2} \mathrm{~S}$ have poor conductivity, which is not conducive to the transmission of electrons and ions [8-10].

To overcome these shortcomings, carbon materials like carbon nanotubes [11], carbon nanofibers [12], hollow carbon spheres [13], and graphene [14,15] have been highlighted for their excellent electrical conductivity and physical adsorption with polysulfides [16,17]. Among these materials, two-dimensional (2D) layered carbon materials have been developed as new energy storage materials. It is known that $2 \mathrm{D}$ carbon materials can achieve a larger specific surface area, providing sufficient active sites and effectively inhibiting the formation of polysulfide intermediates [18-20]. For example, Zheng and co-workers [21] encapsulated graphene in hollow carbon nanosheets (G@HMCN) to prepare 2D carbon core-shell nanosheets. The tightly stacked G@HMCN/S$G$ layered structure promoted the uniform distribution of sulfur without agglomeration. Following 50 cycles, the separator showed no color change, which indicated that self-supporting structures effectively limited sulfur and polysulfide intermediates. Although the ions can migrate freely in the plane of carbon layer, the strictly limited vertical direction presents difficulty in terms of providing interconnected ion transmission paths, which slows the reaction kinetics to some extent $[22,23]$. In this respect, hierarchical porous carbons (HPCs) provide an effective solution due to being internally adjustable $[24,25]$. The interconnected pores in HPCs reduce the shuttle effect through physical confinement and produce fast channels for ion transport. Additionally, the internal spaces provided by the porous structure provide buffer sites for volume expansion and facilitate the transmission of ions and permeation of the electrolyte [26-28]. Accordingly, introducing a porous structure in $2 \mathrm{D}$ carbon materials to form a layered interconnected porous structure can provide a fast path for the migration of electrons, ions, and electrolytes and effectively confine polysulfide shuttling during the charge and discharge cycling process.

Although carbon materials have already demonstrated effective physical adsorption for polysulfides, the weak interaction between non-polar carbon and polar polysulfides still causes polysulfides to escape from carbon materials $[29,30]$. To solve this problem, polar com- pounds comprising metal oxides and sulfides are viewed as important methods for modifying them; these compounds include manganese dioxide $\left(\mathrm{MnO}_{2}\right)$ [31,32], titanium dioxide $\left(\mathrm{TiO}_{2}\right)$ [33], molybdenum disulfide $\left(\mathrm{MoS}_{2}\right)$ [34], and tin disulfide $\left(\mathrm{SnS}_{2}\right)$ [35]. For example, our group designed $\mathrm{MnO}_{2}$ nanosheets on hollow nitrogen-doped microporous carbon (NMRC) via in situ growth to form NMRC/S@MnO $\mathrm{M}_{2}$ for Li-S batteries. The hollow NMRC had an excellent surface area $\left(1999 \mathrm{~m}^{2} \mathrm{~g}^{-1}\right)$ and acceptable pore volume $\left(1.27 \mathrm{~cm}^{3} \mathrm{~g}^{-1}\right)$ with a micropore size of $0.5-2.0 \mathrm{~nm}$ [36]. Compared with metal oxides, metal sulfides not only have an affinity for polysulfides, but also increase the conductivity of electrons and ions in the electrode. In the cycling process, they can act as active sites for the redox reaction of polysulfides, greatly promoting the reaction kinetics of polysulfides [37-39]. Among the known polar materials, $\mathrm{SnS}_{2}$ serves as an effective barrier for restricting the shuttle effect through a strong chemical interaction with polysulfides, largely reducing the loss of active materials. As such, its excellent chemical adsorption allows $\mathrm{SnS}_{2}$ to be developed into new types of Li-S battery host materials [40]. However, most of the synthesized $\mathrm{SnS}_{2}$ structures are in flake structure [41,42]. Although the sheet-like structure greatly increases the specific surface area, its large size increases the time needed for activating the active material and reduces the electrical conductivity [39]. Therefore, developing small-size $\mathrm{SnS}_{2}$ nanostructures is considered an effective strategy for anchoring polysulfides. Such $\mathrm{SnS}_{2}$ nanostructures not only require a shorter excitation time to react with polysulfides, but also provide better opportunities for capturing polysulfides quickly, thus greatly reducing the chance of intermediate products being transferred to the electrolyte $[43,44]$.

Herein, we report the embedding of $\mathrm{SnS}_{2}$ nanoparticles into $2 \mathrm{D}$ porous carbon nanosheet $(\mathrm{PCN})$ interlayers to form a multi-functional ( $\mathrm{PCN}-\mathrm{SnS}_{2}$ ) nanocomposite as an efficient sulfur host for advanced Li-S batteries. Crucially, the multi-functional $\mathrm{PCN}-\mathrm{SnS}_{2}$ nanocomposite material can combine the advantages of the two nanostructured materials to maximize their overall synergistic performance. Small $\mathrm{SnS}_{2}$ nanoparticles can significantly limit polysulfides through chemical adsorption and catalytic reaction, avoiding the back-and-forth movements of polysulfides. The PCN, which has good conductivity and physical adsorption, functions synergistically with the $\mathrm{SnS}_{2}$ nanoparticles, thus greatly reducing the diffusion of polysulfides. The abundant interconnected porous structure shortens the pathway of ion transformation to promote the reaction rate and provides a buffer space for 
volume changes. When applying these characteristics for accelerating electrochemical reaction kinetics, the prepared $\mathrm{PCN}-\mathrm{SnS}_{2}-\mathrm{S}$ cathode exhibited a capacity of $816 \mathrm{~mA} \mathrm{~h} \mathrm{~g}^{-1}$ at the current density of $1 \mathrm{C}(1 \mathrm{C}=$ $1675 \mathrm{~mA} \mathrm{~g}^{-1}$ ) after 100 cycles, significantly better than those of the $\mathrm{SnS}_{2}-\mathrm{S}$ and PCN-S electrodes. Additionally, it achieved a discharge capacity of $650 \mathrm{~mA} \mathrm{~h} \mathrm{~g}^{-1}$ even after 150 cycles at $2 \mathrm{C}$. Our results indicate that small-size $\mathrm{SnS}_{2}$ in PCNs is suitable for fast-charging Li-S batteries and, as such, provides a plausible strategy for the practical application of such batteries.

\section{EXPERIMENTAL SECTION}

\section{Preparation of PCNs}

The PCN nanosheets were obtained via one-step carbonization of adipic acid and zinc powder under argon (Ar) atmosphere as reported in Ref. [45]. The adipic acid and zinc powder were heated to $800^{\circ} \mathrm{C}$ for $2 \mathrm{~h}$ at a heating rate of $6^{\circ} \mathrm{C} \mathrm{min}{ }^{-1}$. After cooling to room temperature, zinc oxide and zinc were removed with $1 \mathrm{~mol} \mathrm{~L}^{-1}$ hydrochloric acid and then dried in an oven at $60^{\circ} \mathrm{C}$ for $24 \mathrm{~h}$.

\section{Preparation of the multi-functional nanocomposite and tin disulfide}

In this study, $30 \mathrm{~mL}$ of deionized water was added to a mixture of tin tetrachloride pentahydrate and thioacetamide (1:2 volume ratio); after stirring, $25 \mathrm{mg}$ of PCNs were added. After sonication, the hydrothermal reaction was performed at $180^{\circ} \mathrm{C}$ for $12 \mathrm{~h}$. The obtained products were washed several times with ethanol and deionized water and then dried in an oven at $60^{\circ} \mathrm{C}$ for $24 \mathrm{~h}$. The preparation of $\mathrm{SnS}_{2}$ was similar but without the addition of 2D PCNs.

\section{Synthesis of $\mathrm{PCN}_{-} \mathrm{SnS}_{2}-\mathrm{S}, \mathrm{SnS}_{2}-\mathrm{S}$, and PCN-S}

The PCN-SnS $2, \mathrm{SnS}_{2}$, or PCN sample was mixed with sulfur powder at a weight ratio of 2:1 and placed in a sealed glass bottle. Using the melt diffusion method, the mixture was heated at $155^{\circ} \mathrm{C}$ for $12 \mathrm{~h}$. Then, it was heated at $200^{\circ} \mathrm{C}$ for $30 \mathrm{~min}$ under $\mathrm{Ar}$ to remove sulfur from the surface.

\section{Adsorption for the $\mathbf{L i}_{2} \mathrm{~S}_{\mathbf{4}}$ solution test}

In a glove box filled with $\mathrm{Ar}$ gas, $\mathrm{Li}_{2} \mathrm{~S}$ and $\mathrm{S}$ were added at a mass ratio of 1:3 to a solution of dimethoxyethane and dioxolane at a 1:1 volume ratio. The mixed solution was stirred for $24 \mathrm{~h}$ in the dark at $60^{\circ} \mathrm{C}$. This led to the formation of a $10 \mathrm{mmol} \mathrm{L}^{-1} \mathrm{Li}_{2} \mathrm{~S}_{4}$ solution. Then, $30 \mathrm{mg}$ of active materials were added to the $10.0 \mathrm{mmol} \mathrm{L}^{-1} \mathrm{Li}_{2} \mathrm{~S}_{4}$ solution and a color change was observed after standing still for $2 \mathrm{~h}$.

\section{Characterizations}

The morphologies of all the products were acquired using a Hitachi S-4800 scanning electron microscope (SEM) with a $5 \mathrm{kV}$ accelerating voltage. High-angle annular dark-field scanning transmission electron microscopy (HAADF-STEM), high-resolution TEM (HRTEM), and selected-area diffraction (SAED) were performed using a Thermo Fisher Talos microscope fitted with a Super-X energy-dispersive X-ray spectroscopy (EDX) system operated at $200 \mathrm{kV}$. Additionally, X-ray diffraction analysis (XRD) was recorded on a D8 Advance X-ray diffractometer (Bruker) with $\mathrm{Cu} \mathrm{Ka}$ radiation $(\lambda=$ $0.1540598 \mathrm{~nm})$ at $40 \mathrm{kV}$ and $40 \mathrm{~mA}$; the $2 \theta$ scanning range was $5^{\circ}-70^{\circ}$. Raman measurements were recorded on a Raman microscope (Renishaw). The surface-element compositions of all the samples were tested by an X-ray photoelectron spectroscope (XPS) (Escalab 250Xi). The specific surface area, pore-size distribution, and pore volume of the sample were measured after degassing under vacuum at $80^{\circ} \mathrm{C}$ for $12 \mathrm{~h}$ using a Micromeritics Tristar II 3020 analyzer. Comprehensive thermogravimetric analysis (TGA) was conducted to determine the sulfur content of the sample under nitrogen flow with a temperature rise rate of $5^{\circ} \mathrm{C} \mathrm{min}^{-1}$. The ultraviolet-visible (UV-Vis) absorption spectra were collected using a UVVis spectrophotometer (Shimadzu) in the range of 350-700 nm.

\section{Electrochemical measurements}

For preparing the working electrode, $N$-methyl pyrrolidone (NMP) was used as a solvent, and the sulfur cathode material ( $\mathrm{PCN}-\mathrm{SnS}_{2}-\mathrm{S}$ and $\mathrm{SnS}_{2}-\mathrm{S}$ ), conductive carbon, and binder polyvinylidene fluoride (PVDF) were combined according to a mass ratio of $8: 1: 1$. The above materials were evenly coated on aluminum foil and vacuumdried at $55^{\circ} \mathrm{C}$ for $12 \mathrm{~h}$. The electrode sheet was obtained by cutting into a $12-\mathrm{mm}$-diameter disc, and the active material loading was approximately $2.6 \mathrm{mg} \mathrm{cm}^{-2}$. A lithium sheet and a Celgard2004 polypropylene (PP) porous membrane were assembled into CR2025 coin cells in an Ar glovebox. In $1.0 \mathrm{~mol} \mathrm{~L}^{-1}$ lithium bis(trifluoromethane sulfonyl)imide (LiTFSI), 1,3-dioxolane was formulated with 1,2-dimethoxyethane (1:1 by volume) and $1 \mathrm{wt} \% \mathrm{LiNO}_{3}$ as an additive. The electrolyte amount in the electrode was approximately $12 \mu \mathrm{L} \mathrm{mg}^{-1}$. The control voltage range was $1.4-2.8 \mathrm{~V}$ (relative to $\mathrm{Li} / \mathrm{Li}^{+}$) under different current densities for constant current charge/ 
discharge tests using the Land CT-2001A battery test system. An electrochemical workstation (Autolab PGSTAT 302N) was used for conducting cyclic voltammetry $(\mathrm{CV})$ at a scan rate of $0.2 \mathrm{mV} \mathrm{s}^{-1}$ between 1.4 and $2.8 \mathrm{~V}$. Electrochemical impedance spectroscopy (EIS) was obtained in the frequency range of $100 \mathrm{kHz}$ to $10 \mathrm{MHz}$.

\section{Density functional theory calculations}

All density functional theory (DFT) calculations were performed using the CASTEP code in Material Studio (2017, Accelrys Inc.), combined with the generalized gradient approximation and Perdew-Burke-Ernzerhof method to check the electron exchange-correlation function of interacting electrons. The system energy convergence was set to $2.0 \times 10^{-6} \mathrm{eV}$ atom $^{-1}$, and the motion energy cut-off was $500 \mathrm{eV}$ for the ultra-soft plane wave. To optimize the structural calculation accuracy, the maximum force tolerance was specified as $0.05 \mathrm{eV}^{-1}$, and the $k$-points in the Brillouin zone were sampled using the Monkhorst-Pack method. We used a $3 \times 3 \times 1$ supercell to represent the relative original unit cell size, combined with the (100) crystal plane and (001) $\mathrm{SnS}_{2}$ crystal plane to create the model. The binding energy $\left(E_{\mathrm{b}}\right)$ between $\mathrm{SnS}_{2}$ and $\mathrm{Li}_{2} \mathrm{~S}_{4}$ molecules was calculated as follows:
$E_{\mathrm{b}}=E_{\mathrm{SnS}_{2}-\mathrm{Li}_{2} \mathrm{~S}_{4}}-E_{\mathrm{SnS}_{2}}-E_{\mathrm{Li}_{2} \mathrm{~S}_{4}}$.

\section{RESULTS AND DISCUSSION}

\section{Structural characterization of the material}

The DFT calculations were conducted first, using the (100) crystal plane and (001) crystal plane of $\mathrm{SnS}_{2}$ as models for calculating the binding energy between $\mathrm{SnS}_{2}$ and $\mathrm{Li}_{2} \mathrm{~S}_{4}$ to show the adsorption effect of $\mathrm{SnS}_{2}$ on polysulfides [37]. The relevant geometry and binding energies are shown in Fig. 1a, b. The $\mathrm{Li}_{2} \mathrm{~S}_{4}$ molecules were chemically adsorbed on the surface of the $\mathrm{SnS}_{2}$ molecules. The most favorable structure was $\mathrm{Li}$ atoms in $\mathrm{Li}_{2} \mathrm{~S}_{4}$ molecules combined with $\mathrm{S}$ atoms in adjacent $\mathrm{SnS}_{2}$ molecules [46]. When $\mathrm{Li}_{2} \mathrm{~S}_{4}$ was adsorbed on the (100) crystal plane surface of $\mathrm{SnS}_{2}$, the shortest distances of Li-Sn, S-Sn, and $\mathrm{Li}-\mathrm{S}$ were $3.37,2.85$, and $2.51 \AA$, respectively. For $\mathrm{Li}_{2} \mathrm{~S}_{4}$ adsorbed on the (001) crystal plane of $\mathrm{SnS}_{2}$, the shortest distances of Li-Sn, S-Sn, and Li-S were 3.46, 4.60, and $2.43 \AA$, respectively. The binding energy between the (100) crystal plane of $\mathrm{SnS}_{2}$ and $\mathrm{Li}_{2} \mathrm{~S}_{4}$ molecules was $1.35 \mathrm{eV}$; this was larger than the binding energy of the (001) crystal plane of $\mathrm{SnS}_{2}$ and $\mathrm{Li}_{2} \mathrm{~S}_{4}$ molecules $(0.81 \mathrm{eV})$. This illustrates that the chemical effect of polysulfide on

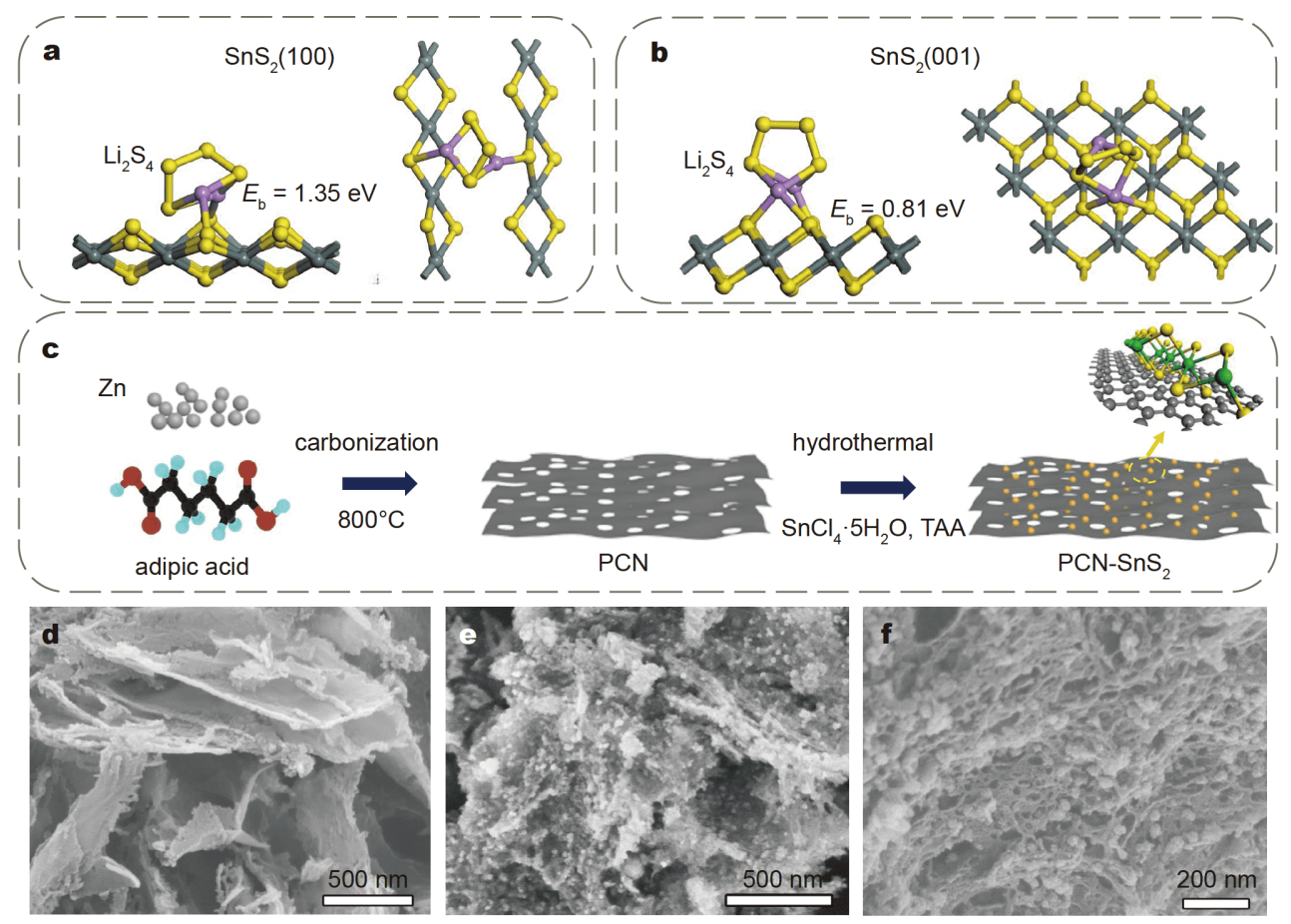

Figure 1 The geometry and energy in the combination of $\mathrm{SnS}_{2}$ and $\mathrm{Li}_{2} \mathrm{~S}_{4}$ molecules of different crystal planes in the DFT calculation (front and top views): (a) $\mathrm{SnS}_{2}$ with a (100) crystal plane and (b) $\mathrm{SnS}_{2}$ with a (001) crystal plane. (c) Schematic illustration of the preparation of PCN-SnS 2 composites (TAA: thioacetamide). SEM images of (d) PCN and (e, f) PCN-SnS 2 . 
the (100) crystal plane of $\mathrm{SnS}_{2}$ was stronger than that on the (001) crystal plane of $\mathrm{SnS}_{2}$, indicating that decreasing the size of $\mathrm{SnS}_{2}$ can effectively shorten the excitation time for capturing and reacting with polysulfides.

Fig. 1c illustrates the synthesis process of PCN-SnS 2 . A simple one-step carbonization method was first conducted to prepare PCNs using adipic acid and zinc powder. Then, the $\mathrm{SnS}_{2}$ nanoparticles were embedded into the PCN layer by a hydrothermal reaction. The layered porous structure of PCNs was able to restrain $\mathrm{SnS}_{2}$ from growing along the $z$-axis, giving rise to largesize nanosheets, and also affected the $\mathrm{SnS}_{2}$ growing along the PCN plane direction due to the porous confinement structure. This subsequently led to the generation of $\mathrm{SnS}_{2}$ nanoparticles.

The SEM image in Fig. 1d shows that the layered porous carbon has an obvious 2D structure with a thickness of $40-50 \mathrm{~nm}$ and good dispersibility, which is conducive for $\mathrm{SnS}_{2}$ loading. Fig. 1e, f show that the grown $\mathrm{SnS}_{2}$ is closely embedded in the layered porous carbon in the nanoparticle morphology with a size of $20-30 \mathrm{~nm}$.
This is further underscored by the TEM observation of PCN-SnS 2 . Fig. 2a shows the HAADF-STEM image of the PCN-SnS ${ }_{2}$ hybrid structure. The corresponding SAED pattern (Fig. 2b) of the entire area in Fig. 2a matches the crystal plane family of $\mathrm{SnS}_{2}$. The HRTEM image (Fig. 2c) shows that the $\mathrm{SnS}_{2}$ nanoparticles are embedded in the PCN [47]. The corresponding fast Fourier transform (FFT) pattern (Fig. 2c, bottom inset) and the enlarged HRTEM image (Fig. 2c, upper inset) show that the nanoparticles are satisfied with the $\mathrm{SnS}_{2}$ (100) crystal lattice plane. The corresponding EDS elemental maps (Fig. 2dg) present the distribution of $\mathrm{C}, \mathrm{Sn}$, and $\mathrm{S}$ elements and further clarify that the $\mathrm{SnS}_{2}$ nanoparticles are successfully embedded in the PCNs. In contrast, the pure $\mathrm{SnS}_{2}$ without embedding in the PCN shows a sheet-like morphology as previously reported [48] with a size between 60 and $200 \mathrm{~nm}$ and tends to agglomerate together (Fig. S1). The TEM, SAED, and HRTEM results (Fig. S2) indicate that the $2 \mathrm{D} \mathrm{SnS}{ }_{2}$ nanosheets maximize the exposed (001) facets. This further confirms that it tends to transform from the typical 2D nanosheets into nanoparticles when
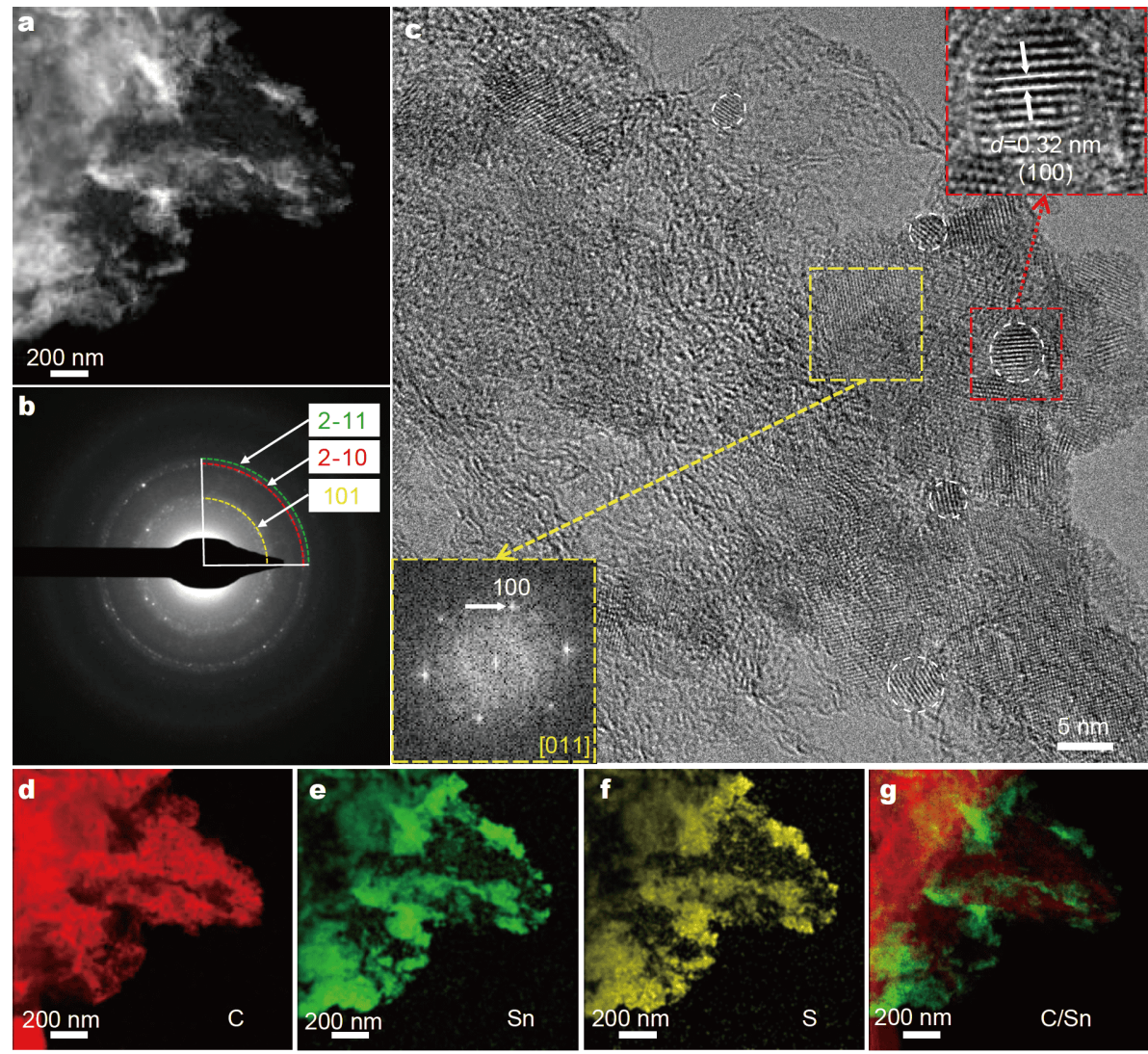

Figure 2 (a) HAADF-STEM image of the PCN-SnS ${ }_{2}$. (b) SAED pattern of the entire area in (a). (c) HRTEM image, the corresponding FFT of the area indicated by the yellow box (bottom inset), and the enlarged HRTEM image of the area indicated by the red box (upper inset). (d-g) The corresponding EDX elemental maps of (a): C (red), Sn (green), and S (yellow). 
$\mathrm{SnS}_{2}$ is constrained in PCNs. This means that the PCNs are able to restrict the growth of $\mathrm{SnS}_{2}$ nanosheets along their (001) crystal plane to form nanoparticles. As previously noted, small-size $\mathrm{SnS}_{2}$ nanoparticles have a higher utilization rate of active materials and shorten the activation time during chemical reactions. Accordingly, the $\mathrm{PCN}-\mathrm{SnS}_{2}$ composite with $\mathrm{SnS}_{2}$ nanoparticles and 2D carbon nanosheets can provide reasonable synergistic properties and multifunctionality to the two nanomaterials [4].

The XRD patterns of the PCN-SnS ${ }_{2}$ and PCN are shown in Fig. 3a. The PCN has a broad diffraction peak centered at $23.5^{\circ}$, corresponding to the (002) crystal plane of graphite. There are no other obvious diffraction peaks in the range of $10^{\circ}-70^{\circ}$, indicating high-purity PCNs [45]. In the Raman spectrum (Fig. S3), the D-band $\left(\sim 1334 \mathrm{~cm}^{-1}\right)$ and G-band $\left(\sim 1595 \mathrm{~cm}^{-1}\right)$ correspond to $\mathrm{sp}^{3}$-hybridized carbon defects and $\mathrm{sp}^{2}$-hybridized graphitized carbon, respectively. The $I_{\mathrm{D}} / I_{\mathrm{G}}$ (the ratio of the intensities of D-band to G-band) value of $\mathrm{PCN}$ is 0.96 , indicating relatively high graphitization [36]. Once $\mathrm{SnS}_{2}$ had been embedded in the PCN, the diffraction patterns of $\mathrm{SnS}_{2}$ exhibited broad peaks. This indicates that the presence of porous PCN inhibits the growth of $\mathrm{SnS}_{2}$, leading to their smaller size. This result is consistent with the SEM and TEM observations.
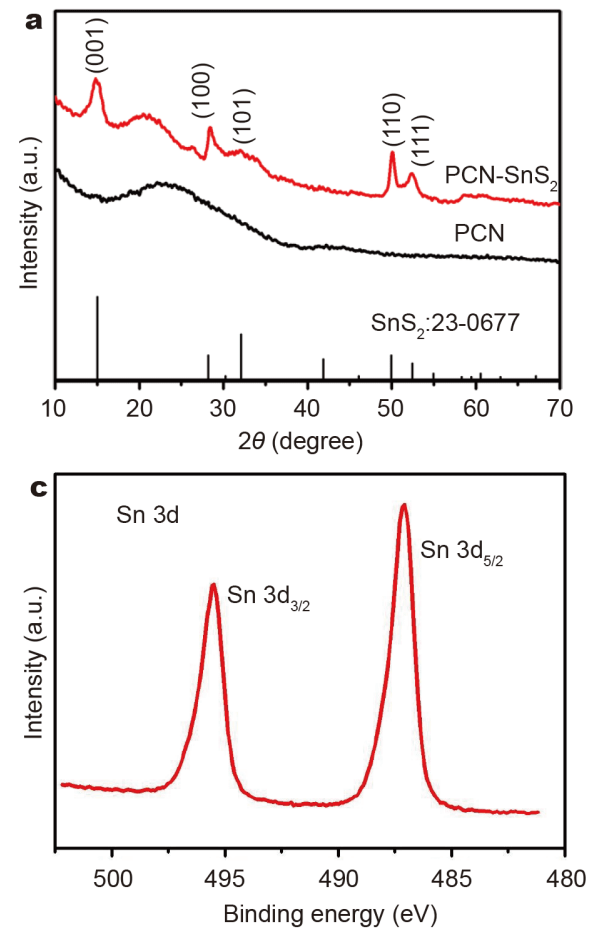

The surface-element composition and the chemical state of PCN-SnS ${ }_{2}$ were further investigated by XPS. The full spectrum of PCN-SnS 2 (Fig. S4) exhibits the presence of $\mathrm{C}, \mathrm{Sn}, \mathrm{S}$, and O elements. The C 1s spectrum of PCN$\mathrm{SnS}_{2}$ can be divided into three peaks (Fig. 3b), respectively, corresponding to $\mathrm{C}=\mathrm{C}(284.8 \mathrm{eV}), \mathrm{C}-\mathrm{C}(285.6 \mathrm{eV})$, and $\mathrm{C}=\mathrm{O}(287.6 \mathrm{eV})$ [47]. The two peaks at 487.1 and $495.5 \mathrm{eV}$ (Fig. 3c) of Sn 3d spectrum correspond to Sn $3 d_{5 / 2}$ and $S n 3 d_{3 / 2}$, respectively, indicating the presence of $\mathrm{Sn}^{4+}$ in $\mathrm{PCN}-\mathrm{SnS}_{2}$ [49]. The S $2 \mathrm{p}$ spectrum is divided into five peaks (Fig. 3d). Both peaks at 162.0 and $163.1 \mathrm{eV}$ correspond to the presence of $\mathrm{S}^{2-}$ in $\mathrm{PCN}-\mathrm{SnS}_{2}$. The peaks at 164.2 and $165.4 \mathrm{eV}$ confirm the presence of the C-S-C bond in $\mathrm{PCN}-\mathrm{SnS}_{2}$, suggesting that $\mathrm{SnS}_{2}$ nanoparticles are tightly bound to the porous $2 \mathrm{D}$ carbon nanosheets. This is beneficial for limiting the shuttling effect of polysulfides. The peak at $169.5 \mathrm{eV}$ is attributed to the S-O bond owing to the sulfur oxidation in the air $[11,35,50]$.

The $\mathrm{N}_{2}$ adsorption-desorption measurement was conducted for PCN, $\mathrm{SnS}_{2}$, and $\mathrm{PCN}-\mathrm{SnS}_{2}$. The isotherms of $\mathrm{PCN}$ and $\mathrm{PCN}-\mathrm{SnS}_{2}$ show that the typical type IV isothermal hysteresis loops (Fig. S5a, c), indicating the mesoporous structures of PCN and PCN-SnS ${ }_{2}$. Furthermore, their adsorption lines at a higher relative pressure $\left(P / P_{0} \sim\right.$ 1.0) are almost vertical, revealing the presence of macropores [45]. The PCN has a hierarchically porous
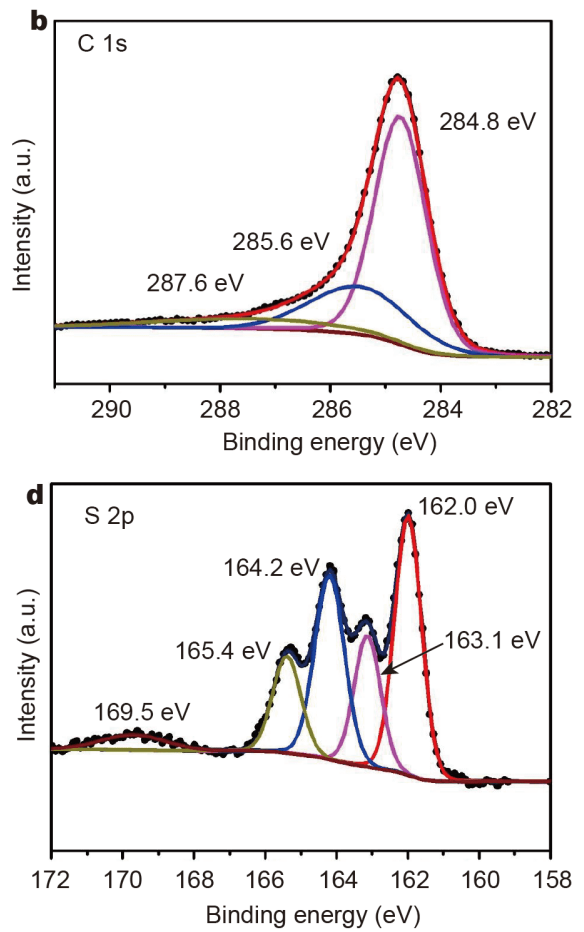

Figure 3 (a) The XRD patterns of PCN-SnS ${ }_{2}$ and PCN. (b-d) High-resolution XPS spectra of C 1s, Sn 3d, and S 2p of PCN-SnS ${ }_{2}$, respectively. 
structure with pore sizes of 6.4 and $34.7 \mathrm{~nm}$, a specific surface area of $1473.7 \mathrm{~m}^{2} \mathrm{~g}^{-1}$, and a pore volume of $3.8 \mathrm{~cm}^{3} \mathrm{~g}^{-1}$. Following $\mathrm{SnS}_{2}$ nanoparticles' embedding, the specific surface area of $\mathrm{PCN}-\mathrm{SnS}_{2}$ decreases to $447.5 \mathrm{~m}^{2} \mathrm{~g}^{-1}$ and its pore volume reduces to $0.9 \mathrm{~cm}^{3} \mathrm{~g}^{-1}$. The pore sizes of $\mathrm{PCN}-\mathrm{SnS}_{2}$ are 3.7 and $38.4 \mathrm{~nm}$ (Fig. S5d); as such, it has retained a hierarchically porous structure, which is helpful for sulfur loading. The reduced mesopore at $3.7 \mathrm{~nm}$ is expected to have been formed by the dispersed $\mathrm{SnS}_{2}$ nanoparticles that do not completely occupy the mesopores of PCN. However, the specific surface area of pure $\mathrm{SnS}_{2}$ is only $14.3 \mathrm{~m}^{2} \mathrm{~g}^{-1}$ with a pore volume of $0.09 \mathrm{~cm}^{3} \mathrm{~g}^{-1}$. Therefore, the PCN-SnS 2 still has a multi-layered and rich hierarchically porous structure that is able to promote the sulfur content and provides more space for supporting the conversion of polysulfides.

After sulfur loading, the XRD pattern of $\mathrm{PCN}-\mathrm{SnS}_{2}-\mathrm{S}$ (Fig. S6) displays only slight diffraction peaks for elemental sulfur, indicating that most of the sulfur has filled in the porous structure of $\mathrm{PCN}-\mathrm{SnS}_{2}$. According to the results of the TGA curve (Fig. S7), the PCN-S has $67 \mathrm{wt} \%$ sulfur, and $\mathrm{PCN}-\mathrm{SnS}_{2}-\mathrm{S}$ has $65 \mathrm{wt} \%$ sulfur. Both are higher than the $56 \mathrm{wt} \%$ of $\mathrm{SnS}_{2}-\mathrm{S}$. This is attributed to the hierarchically porous structure of PCN and PCN-SnS which provides sufficient space for sulfur-filling.

\section{Electrochemical performance}

The electrochemical performance of the multi-level PCN$\mathrm{SnS}_{2}-\mathrm{S}$ as a sulfur cathode was evaluated. Fig. 4a shows the CV performance of the first three cycles of the PCN$\mathrm{SnS}_{2}-\mathrm{S}$ electrode and presents two reduction peaks and one oxidation peak. During the discharge, the first peak at $2.23 \mathrm{~V}$ corresponds to the conversion of sulfur to longchain polysulfides $\left(\mathrm{Li}_{2} \mathrm{~S}_{x}, 4 \leq x<8\right)$; the second peak at $1.96 \mathrm{~V}$ is the conversion of long-chain polysulfides to short-chain polysulfide $\left(\mathrm{Li}_{2} \mathrm{~S}_{x}, 1 \leq x<4\right)$. During the charging process, the reverse process is where the shortchain polysulfides are oxidized to long-chain polysulfides at approximately $2.47 \mathrm{~V}$ [51]. These peaks at the second and the third cycles are almost overlapped, confirming the excellent electrochemical stability of the PCN-SnS ${ }_{2}-\mathrm{S}$ composite.

Fig $4 \mathrm{~b}$ presents the rate performances of PCN-S, $\mathrm{SnS}_{2}-\mathrm{S}$, and $\mathrm{PCN}-\mathrm{SnS}_{2}-\mathrm{S}$ electrodes. It shows that the PCN-SnS $2-\mathrm{S}$ electrode has reversible capacities of $1223,1106,996,913$, and $823 \mathrm{~mA} \mathrm{~h} \mathrm{~g}^{-1}$ at the rates of $0.1,0.2,0.5,1$, and $2 \mathrm{C}$ $\left(1 \mathrm{C}=1675 \mathrm{~mA} \mathrm{~g}^{-1}\right)$, respectively. In contrast, the $\mathrm{SnS}_{2}-\mathrm{S}$ composite shows the reversible capacities of 1140,879 , 744, 646, and $545 \mathrm{~mA} \mathrm{~h} \mathrm{~g}^{-1}$ at $0.1,0.2,0.5,1$, and $2 \mathrm{C}$, respectively. The PCN-S electrode indicates inferior re- versible capacities of $772,712,613,546$, and $455 \mathrm{~mA} \mathrm{~h} \mathrm{~g}^{-1}$ at $0.1,0.2,0.5,1$, and $2 \mathrm{C}$, respectively. It is worth noting that at the start of the discharge, the capacity of the $\mathrm{SnS}_{2}-\mathrm{S}$ electrode decreases significantly compared with the other two electrodes. This is considered a reasonable effect. On one hand, the large size of $\mathrm{SnS}_{2}$ prolongs the activation time for the chemical adsorption of polysulfides $[39,43,44]$. Conversely, the nonporous $\mathrm{SnS}_{2}$ creates almost all the sulfur at the surface. The sulfur in $\mathrm{SnS}_{2}-\mathrm{S}$ has direct contact with the electrolyte, leading to polysulfide shuttling between the electrodes. Thus, the capacity of the $\mathrm{SnS}_{2}-\mathrm{S}$ electrode becomes stable after the activation of $\mathrm{SnS}_{2}$. Compared with the $\mathrm{SnS}_{2}-\mathrm{S}$ electrode, the chemical adsorption of small $\mathrm{SnS}_{2}$ nanoparticles in $\mathrm{PCN}-\mathrm{SnS}_{2}-\mathrm{S}$ is easily activated and the discharge capacity always remains stable. In addition, the rate performances of the three samples show that the chemical adsorption of $\mathrm{SnS}_{2}$ for polysulfides is better than the physical confinement of PCNs. Therefore, the capacity of the $\mathrm{PCN}_{-} \mathrm{SnS}_{2}-\mathrm{S}$ electrode is greatly improved due to its dual physical-chemical confinement, which can anchor polysulfides and promote the transport of ions and electrons. Accordingly, the PCN-SnS ${ }_{2}-\mathrm{S}$ electrode still demonstrates a capacity of $1040 \mathrm{~mA} \mathrm{~h} \mathrm{~g}^{-1}$, while the $\mathrm{SnS}_{2}-\mathrm{S}$ and PCN-S electrodes exhibit only 826 and $692 \mathrm{~mA} \mathrm{~h} \mathrm{~g}^{-1}$, when the current density returns to $0.1 \mathrm{C}$.

Fig 4c compares the performances of the $\mathrm{PCN}-\mathrm{SnS}_{2}-\mathrm{S}$, $\mathrm{SnS}_{2}-\mathrm{S}$, and PCN-S electrodes at a current density of $1 \mathrm{C}$ for 100 cycles. All of the electrodes were activated at $0.1 \mathrm{C}$ for one cycle. After one cycle of $0.1 \mathrm{C}$ activation, the $\mathrm{PCN}_{-} \mathrm{SnS}_{2}-\mathrm{S}$ electrode achieved an initial discharge capacity of $1135 \mathrm{~mA} \mathrm{~h} \mathrm{~g}^{-1}$ at $1 \mathrm{C}$ and maintained a capacity of $816 \mathrm{~mA} \mathrm{~h} \mathrm{~g}^{-1}$ after 100 cycles. The capacity was only 460 and $277 \mathrm{~mA} \mathrm{~h} \mathrm{~g}^{-1}$ for the $\mathrm{SnS}_{2}-\mathrm{S}$ and PCN-S electrodes. Similar to the rate performance of $\mathrm{SnS}_{2}$, the $\mathrm{SnS}_{2}-\mathrm{S}$ electrode displayed fast capacity decay in the first ten cycles. After the initial ten cycles, the chemical adsorption ability of $\mathrm{SnS}_{2}$ was activated, giving rise to stable capacity. In addition, the excellent conductivity of the PCNs in the PCN-SnS - -S electrode promoted the fast transport of electrons and ions, and the capacity decayed slowly in the first few cycles of discharge. For the PCN-S electrode, the only physical confinement is less successful in limiting polysulfide, causing its capacity to gradual decrease. This result confirms that the $\mathrm{PCN}-\mathrm{SnS}_{2}-\mathrm{S}$ with dual physicalchemical confinement for polysulfides is more effective than the chemical adsorption of $\mathrm{SnS}_{2}-\mathrm{S}$ and the physical adsorption of PCN-S, which is consistent with the rate performance result.

More importantly, when the current density reached 

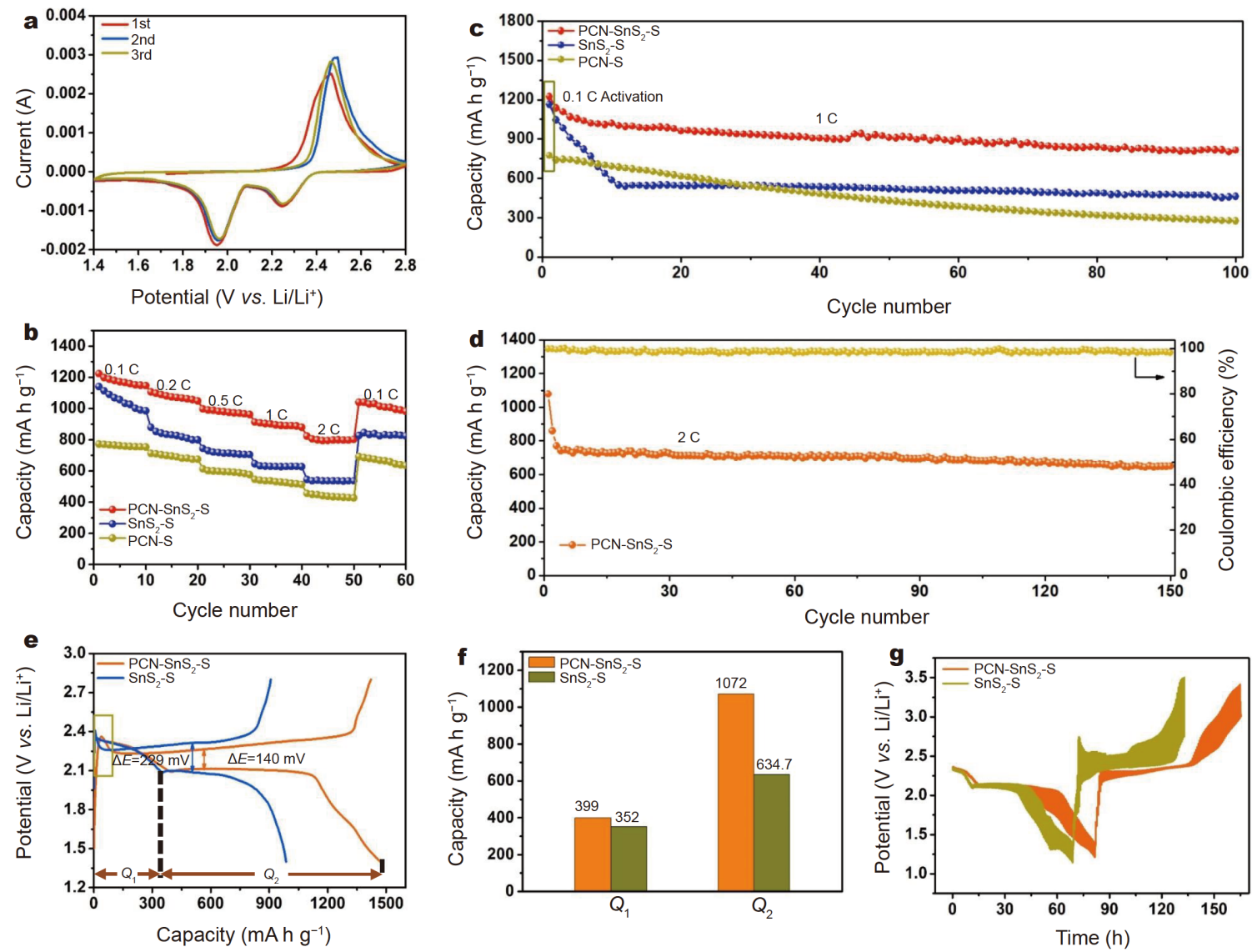

Figure 4 (a) The CV curves of the PCN-SnS ${ }_{2}-\mathrm{S}$ electrode at $1.4-2.8 \mathrm{~V}$ at a potential sweep rate of $0.2 \mathrm{mV} \mathrm{s}^{-1}$. (b) The rate performances of the PCN$\mathrm{S}, \mathrm{SnS}_{2}-\mathrm{S}$, and PCN-SnS 2 -S electrodes at various current densities. (c) The cycling performance of the PCN-S, SnS ${ }_{2}-\mathrm{S}$, and PCN-SnS $2-\mathrm{S}$ cathodes at $1 \mathrm{C}$ for 100 cycles after the initial activation at $0.1 \mathrm{C}$ for one cycle. (d) The cycling performance of the PCN-SnS $-\mathrm{S}$ electrode at $2 \mathrm{C}$ for 150 cycles. (e) The first cycle of the charge/discharge profiles of the $\mathrm{PCN}-\mathrm{SnS}_{2}-\mathrm{S}$ electrode at $0.2 \mathrm{C}$. (f) The corresponding discharge capacity of the two plateaus. (g) The charge-discharge GITT profiles for the $\mathrm{PCN}-\mathrm{SnS}_{2}-\mathrm{S}$ and $\mathrm{SnS}_{2}$-S electrodes at $0.05 \mathrm{C}$.

$2 \mathrm{C}$, the $\mathrm{PCN}-\mathrm{SnS} \mathrm{S}_{2}-\mathrm{S}$ electrode only needed three cycles to be activated to maintain a stable reversible capacity. Fig. $4 \mathrm{~d}$ shows that the $\mathrm{PCN}-\mathrm{SnS}_{2}-\mathrm{S}$ electrode remained at $650 \mathrm{~mA} \mathrm{~h} \mathrm{~g}^{-1}$ after 150 cycles at a high current density of $2 \mathrm{C}$. This is attributed to the unique hierarchically porous structure that enables a good fast-charging performance for the $\mathrm{PCN}-\mathrm{SnS}_{2}$-S electrode. The graphitized carbon helps to improve the overall conductivity of the material. Additionally, the 2D carbon nanosheets were equipped with abundant porous structures to provide the ions with a fast interconnecting channel. Moreover, the strong chemical adsorption of $\mathrm{SnS}_{2}$ nanoparticles and the physical adsorption of PCN, enabled by multi-dimensional common adsorption, greatly reduce the occurrence of shuttle effects. Overall, this design delivers better electrochemical performance compared with previous reports on Sn-based compounds (Table 1).

Having established that the PCN-SnS 2 -S electrode de- livered an excellent electrochemical performance at high current densities, we subsequently discussed the mechanism at a small current density of $0.2 \mathrm{C}$. Fig. $4 \mathrm{e}$ shows the first cycle charge and discharge plateau at $0.2 \mathrm{C}$. The discharge platforms at 2.31 and $2.10 \mathrm{~V}$ correspond to the two reduction peaks, and the charge platform at $2.28 \mathrm{~V}$ corresponds to the oxidation peak in Fig. 4a. The PCN$\mathrm{SnS}_{2}$-S electrode shows a small voltage difference of $140 \mathrm{mV}$, indicating a stable charge and discharge process and faster reaction kinetics [59]. The $\mathrm{SnS}_{2}$-S electrode exhibits a higher voltage difference $(229 \mathrm{mV})$. This indicates that the reaction kinetics in $\mathrm{SnS}_{2}$-S is slower and, as a result, could not effectively promote the conversion of polysulfides. The activation barrier (green rectangular area in Fig. 4e) shows that the PCN-SnS 2 has a smaller potential barrier compared with pure $\mathrm{SnS}_{2}$. According to a previous report [60], this is derived from a catalytic effect, which helps promote the conversion of poly- 
Table 1 Electrochemical performance comparisons among the reported Sn-based compounds

\begin{tabular}{|c|c|c|c|c|}
\hline Host materials & Current rate $(\mathrm{C})$ & Cycle number & Reversible capacity ( $\mathrm{mA} \mathrm{h}^{-1}$ ) & Ref. \\
\hline $\mathrm{SnS}_{2} / \mathrm{CNTs} / \mathrm{S}$ & 0.1 & 100 & 1002.3 & {$[52]$} \\
\hline $\mathrm{SnO}_{2} @ \mathrm{rGO} / \mathrm{CNTs} / \mathrm{S}$ & 0.1 & 50 & 958.6 & {$[53]$} \\
\hline S/(T-PPy)@SnO & 0.2 & 200 & 873.2 & {$[54]$} \\
\hline $\mathrm{C} @ \mathrm{SnO}_{2} / \mathrm{S}$ & 0.2 & 100 & 1105.2 & {$[55]$} \\
\hline $\mathrm{NG} / \mathrm{SnS}_{2} / \mathrm{TiO}_{2}-\mathrm{S}$ & 0.2 & 100 & 739 & {$[56]$} \\
\hline S/AHCNS-SnS ${ }_{2}$ & 0.2 & 100 & 970 & {$[35]$} \\
\hline $\mathrm{SnS}_{2} @ \mathrm{~N}-\mathrm{CNFs}$ & 0.2 & 150 & 889 & {$[57]$} \\
\hline $\mathrm{SnS}_{2}-\mathrm{ND} @ \mathrm{G}$ & 0.2 & 300 & 1016 & {$[44]$} \\
\hline S/NCNT@Co-SnS ${ }_{2}$ & 0.26 & 100 & 1004.3 & {$[40]$} \\
\hline $\mathrm{SnS}_{2} / \mathrm{S} / \mathrm{C}$ & 0.5 & 50 & 875 & {$[37]$} \\
\hline $\mathrm{S} / \mathrm{C}-\mathrm{SnS}{ }_{2}$ & 0.5 & 300 & 800 & [49] \\
\hline $\mathrm{S} / \mathrm{SnO}_{2} @ \mathrm{C}$ & 0.96 & 100 & 674 & {$[58]$} \\
\hline $\mathrm{PCN}-\mathrm{SnS}_{2}-\mathrm{S}$ & 1.0 & 100 & 816 & This work \\
\hline $\mathrm{PCN}-\mathrm{SnS}_{2}-\mathrm{S}$ & 2.0 & 150 & 650 & This work \\
\hline
\end{tabular}

sulfides. In Fig. 4e, the discharge capacity corresponding to the upper-plateau during the discharge process is marked as $Q_{1}$, and $Q_{2}$ is the discharge capacity of the lower plateau. The $Q_{1}$ and $Q_{2}$ values of the PCN-SnS $2-S$ and $\mathrm{SnS}_{2}-\mathrm{S}$ electrodes are shown in Fig. 4f. Concurrently, the ratio of the $Q_{2} / Q_{1}$ value can measure the catalytic conversion rate and reaction kinetics of polysulfides [57]. The $Q_{2} / Q_{1}$ value of the PCN-SnS 2 -S electrode is 2.69 and that of the $\mathrm{SnS}_{2}-\mathrm{S}$ electrode is 1.80 . This indicates that embedding small-size $\mathrm{SnS}_{2}$ nanoparticles in porous $2 \mathrm{D}$ carbon nanosheets can promote the conversion of polysulfides and improve the kinetics of electrochemical reactions. The constant conversion of polysulfides on PCN$\mathrm{SnS}_{2}$ to the final $\mathrm{Li}_{2} \mathrm{~S}$ product helps decrease the shuttle effect of polysulfides during the cycling process. The $\mathrm{PCN}_{-} \mathrm{SnS}_{2}$ with dual physical-chemical confinement demonstrates the best performance.

The galvanostatic intermittent titration technique (GITT) was used to measure the lithium-ion diffusion coefficient during charge and discharge. The GITT measurements were obtained by applying a constant current of $0.05 \mathrm{C}$ for $10 \mathrm{~min}$, followed by a 30 -min rest. The diffusion coefficient of lithium ions $\left(D_{\mathrm{Li}^{+}}\right)$was calculated based on the following formula [61]:

$D_{\mathrm{Li}^{+}}=\frac{4}{\pi \tau}\left(\frac{m_{\mathrm{B}} V_{\mathrm{m}}}{M_{\mathrm{B}} S}\right)^{2}\left(\frac{\Delta E_{\mathrm{s}}}{\Delta E_{\mathrm{t}}}\right)^{2}$,

where $\tau$ is the time of applying current $(s), m_{\mathrm{B}}$ is the weight of active sulfur material $(\mathrm{g}), V_{\mathrm{m}}$ is the molar volume of active sulfur material $\left(\mathrm{cm}^{3} \mathrm{~mol}^{-1}\right), M_{\mathrm{B}}$ is the atomic weight of active sulfur material $\left(\mathrm{g} \mathrm{mol}^{-1}\right), S$ is the effective contact area $\left(\mathrm{cm}^{2}\right)$ between the electrode and the electrolyte, $\Delta E_{s}$ is the voltage difference when the adjacent pulses are terminated, and $\Delta E_{\mathrm{t}}$ is the constant current voltage change that eliminates the $i R$ drop. The charge and discharge GITT curves of PCN-SnS $2-S$ and $\mathrm{SnS}_{2}-\mathrm{S}$ as cathodes are shown in Fig. 4g. The PCN-SnS ${ }_{2}-\mathrm{S}$ electrode has a longer discharge and charge platform and is consistent with the discharge and charge plateau shown in Fig. 4e. The $D_{\mathrm{Li}}{ }^{+}$graph is shown in Fig. S8. The $D_{\mathrm{Li}^{+}}$value of the $\mathrm{PCN}-\mathrm{SnS}_{2}-\mathrm{S}$ electrode ranges from $10^{-11}$ to $10^{-9} \mathrm{~cm}^{2} \mathrm{~s}^{-1}$, while the $D_{\mathrm{Li}^{+}}$value of the $\mathrm{SnS}_{2}-\mathrm{S}$ electrode is approximately $10^{-13} \mathrm{~cm}^{2} \mathrm{~s}^{-1}$. The $\mathrm{Li}^{+}$de-intercalation and intercalation in the $\mathrm{PCN}-\mathrm{SnS}_{2}-\mathrm{S}$ electrode is faster compared with the $\mathrm{SnS}_{2}$-S electrode during the cycling process [62]. This confirms that the $\mathrm{PCN}-\mathrm{SnS}_{2}-\mathrm{S}$ electrode has faster electrochemical redox reaction kinetics due to the multi-functional nanocomposite, which is achieved by embedding smaller $\mathrm{SnS}_{2}$ nanoparticles in 2D PCNs; this provides fast channels for the transport of electrons and ions and promotes the electrochemical reaction process, which, in turn, gives rise to the excellent cycle performance of $\mathrm{PCN}-\mathrm{SnS}_{2}-\mathrm{S}$ at high current densities.

Fig. S9 shows the EIS before and after electrochemical cycling. The diameter of the semicircle in the highfrequency region represents the charge transfer resistance $\left(R_{\mathrm{ct}}\right)$ of the electrode/electrolyte interface, and the oblique line in the low-frequency region corresponds to the Warburg diffusion resistance $\left(R_{\mathrm{d}}\right)$ [63,64]. The $R_{\text {ct }}$ value of the $\mathrm{PCN}-\mathrm{SnS}_{2}-\mathrm{S}$ electrode before the cycle is much lower compared with that of the $\mathrm{SnS}_{2}$-S electrode and the 
slope of $R_{\mathrm{d}}$ is greater compared with that of the $\mathrm{SnS}_{2}-\mathrm{S}$ electrode. After the cycle, the $R_{\mathrm{ct}}$ value of the $\mathrm{PCN}-\mathrm{SnS}_{2}-\mathrm{S}$ electrode is still smaller than that of the $\mathrm{SnS}_{2}-\mathrm{S}$ electrode, indicating that $\mathrm{PCN}-\mathrm{SnS}_{2}$ has a strong infiltration effect as a sulfur body and an electrolyte, which can promote the rapid transmission of ions and improve the redox kinetics. These results are consistent with the GITTmeasured $\mathrm{Li}^{+}$diffusion coefficient.

To further substantiate the adsorption of $\mathrm{PCN}_{-} \mathrm{SnS}_{2}$ on polysulfides, we added the same amount of PCNs, $\mathrm{SnS}_{2}$, and $\mathrm{PCN}-\mathrm{SnS}_{2}$ to the $\mathrm{Li}_{2} \mathrm{~S}_{4}$ solution. Fig. 5a shows the resulting color changes. After $2 \mathrm{~h}$, the $\mathrm{PCN}-\mathrm{SnS}_{2}$ solution became significantly lighter, almost transparent compared with the other two solutions. Fig. 5b illustrates the $\mathrm{UV}-\mathrm{V}$ is spectroscopy to show the strong adsorption capacity of $\mathrm{PCN}-\mathrm{SnS} \mathrm{S}_{2}$ for $\mathrm{Li}_{2} \mathrm{~S}_{4}$. It shows that the $\mathrm{Li}_{2} \mathrm{~S}_{4}$ solution has a strong absorption peak in the $400-450 \mathrm{~nm}$ region $[32,36]$. The absorption peak of $\mathrm{S}_{4}{ }^{2-}$ weakens following the addition of the samples. The adsorption capacity of $\mathrm{PCN}-\mathrm{SnS}_{2}$ is $92 \%$, which is significantly higher than that of $\mathrm{SnS}_{2}(73 \%)$ and PCN (51\%), confirming its strong adsorption capability for polysulfides.
The XPS test was performed on the precipitate following the adsorption experiment (Fig. S10). The two peaks at 487.1 and $495.5 \mathrm{eV}$ correspond to $\mathrm{Sn} 3 \mathrm{~d}_{5 / 2}$ and $\mathrm{Sn}$ $3 \mathrm{~d}_{3 / 2}$, respectively. After the addition of the $\mathrm{Li}_{2} \mathrm{~S}_{4}$ solution, the $3 \mathrm{~d}_{5 / 2}$ and $3 \mathrm{~d}_{3 / 2}$ peaks drop to lower binding energies, decreasing by 0.5 and $0.4 \mathrm{eV}$, respectively. The reduced binding energy confirms the presence of a chemical interaction between $\mathrm{SnS}_{2}$ nanoparticles and $\mathrm{Li}_{2} \mathrm{~S}_{4}$ [44,60], which is consistent with our calculations. These results highlight that the smaller size of $\mathrm{SnS}_{2}$ nanoparticles makes it easier for them to chemically adsorb polysulfides and bond with the physical adsorption of carbon to form a dual physical-chemical constraint of $\mathrm{Li}_{2} \mathrm{~S}_{4}$.

Fig. $5 \mathrm{c}$ illustrates the mechanism of the conversion process of sulfur on $\mathrm{PCN}-\mathrm{SnS}_{2}$. During the discharge process, the physical confinement effect of the abundant pore structure contained in PCNs and the polar chemical effect of the small-sized $\mathrm{SnS}_{2}$ nanoparticles jointly limit the polysulfide, which significantly reduces the diffusion of polysulfide into the electrolyte, thereby reducing the decay of the capacity and loss of the active material. In addition, the $\mathrm{SnS}_{2}$ nanoparticles are able to provide a
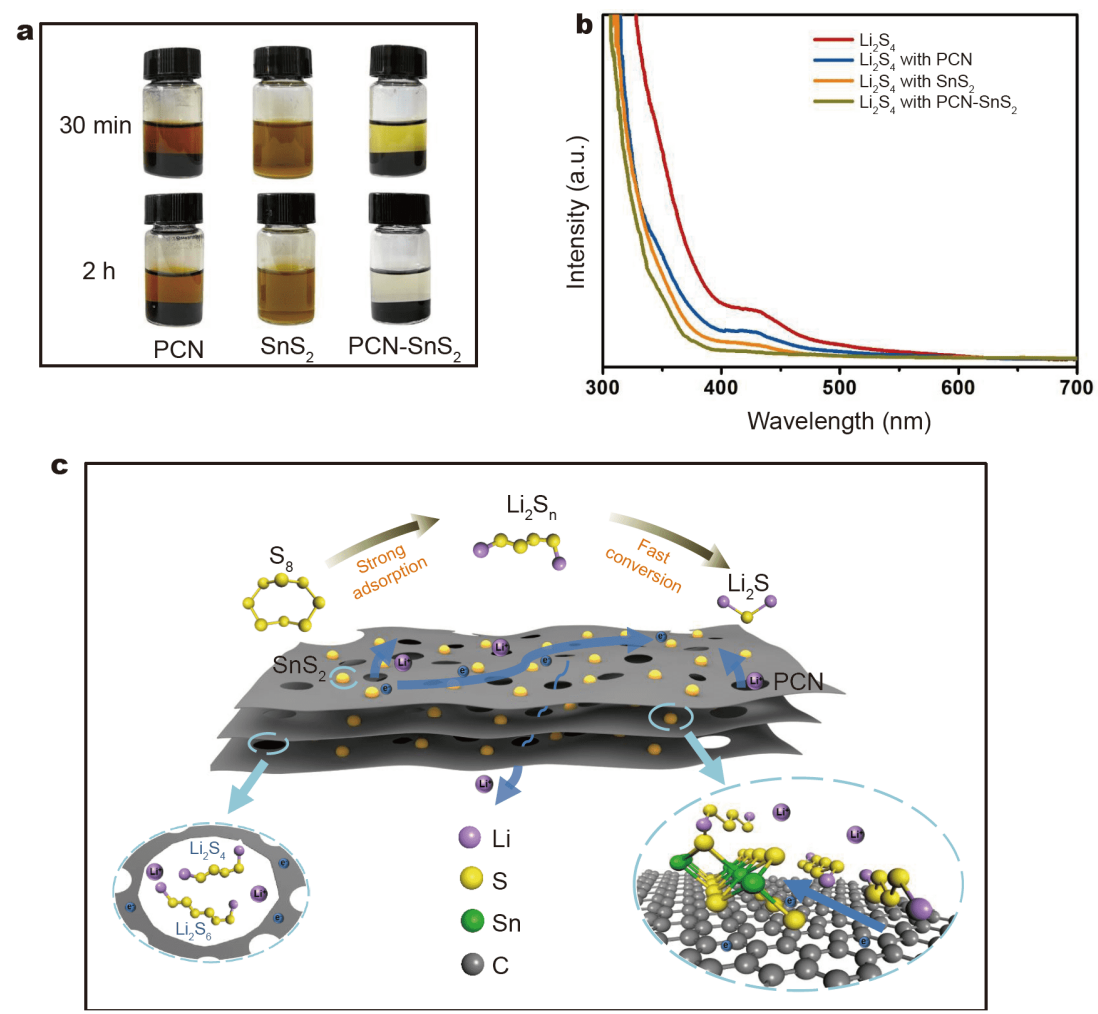

Figure 5 (a) Digital images of the adsorption tests with PCN-SnS ${ }_{2}, \mathrm{SnS}_{2}$, and PCN in a $\mathrm{Li}_{2} \mathrm{~S}_{4}$ solution after 30 min and $2 \mathrm{~h}$. (b) The UV-Vis spectra comparison of $\mathrm{Li}_{2} \mathrm{~S}_{4}, \mathrm{Li}_{2} \mathrm{~S}_{4}$ with $\mathrm{PCN}, \mathrm{Li}_{2} \mathrm{~S}_{4}$ with $\mathrm{SnS}_{2}$, and $\mathrm{Li}_{2} \mathrm{~S}_{4}$ with $P C N-\mathrm{SnS}_{2}$ for $2 \mathrm{~h}$. (c) Schematic illustration of the conversion process of sulfur on $\mathrm{SnS}_{2}$ embedded in PCNs. 
catalytic effect to promote the conversion of polysulfides. The combination of porous PCN and $\mathrm{SnS}_{2}$ nanoparticles promotes the rapid conversion of long-chain polysulfides into $\mathrm{Li}_{2} \mathrm{~S}$ and is fixed on the cathode. The improvement of chemical reaction kinetics will hinder the transfer of polysulfides to the lithium anode. Accordingly, the shuttle effect during the entire discharge process is greatly reduced and the electrochemical performance of the PCN$\mathrm{SnS}_{2}$-S electrode is largely enhanced.

\section{CONCLUSIONS}

In summary, we embedded small $\mathrm{SnS}_{2}$ nanoparticles within the interlayers of $2 \mathrm{D}$ PCNs to form a multifunctional PCN-SnS ${ }_{2}$ nanocomposite. Graphitized carbon nanosheets improved the conductivity of the electrode, and the rich porous structure alleviated volume changes during charge and discharge and provided fast channels for ion transport and electrolyte penetration. The small $\mathrm{SnS}_{2}$ nanoparticles shortened the activation time in the reaction process and improved the utilization rate of adsorbed polysulfides. The layered carbon nanosheets encapsulated $\mathrm{SnS}_{2}$ nanoparticles to synergize the properties of the two materials. That is, the chemical interaction of $\mathrm{SnS}_{2}$ and the physical adsorption of the 2D PCNs enabled a chemical-physical co-capture of polysulfides, thus greatly reducing the shuttle effect. The GITT calculation confirmed that the PCN-SnS ${ }_{2}-\mathrm{S}$ electrode achieved a higher lithium-ion transfer rate compared with the $\mathrm{SnS}_{2}$-S electrode by reducing the electrochemical reaction barrier and improving the electrochemical reaction kinetics. Therefore, the $\mathrm{PCN}-\mathrm{SnS}_{2}-\mathrm{S}$ electrode remained at a discharge capacity of $816 \mathrm{~mA} \mathrm{~h} \mathrm{~g}^{-1}$ at $1 \mathrm{C}$ after 100 cycles. At a high current density of $2 \mathrm{C}$, it still retained a discharge capacity of $650 \mathrm{~mA} \mathrm{~h} \mathrm{~g}^{-1}$, even after 150 cycles.

The current paper substantiates that small $\mathrm{SnS}_{2}$ nanoparticles embedded in 2D PCNs can synergize the performance of the materials for fast-charging Li-S batteries. As such, optimizing the size and content of $\mathrm{SnS}_{2}$ nanoparticles and studying their catalytic activity will help to open up new directions for the development of efficient portable energy storage devices.

Received 7 January 2021; accepted 18 March 2021; published online 27 May 2021

1 Manthiram A, Chung SH, Zu C. Lithium-sulfur batteries: Progress and prospects. Adv Mater, 2015, 27: 1980-2006

2 Zhong $\mathrm{Y}, \mathrm{Xu} \mathrm{X}$, Liu $\mathrm{Y}$, et al. Recent progress in metal-organic frameworks for lithium-sulfur batteries. Polyhedron, 2018, 155: 464-484

3 Zheng Y, Zheng S, Xue H, et al. Metal-organic frameworks for lithium-sulfur batteries. J Mater Chem A, 2019, 7: 3469-3491

4 Jana M, Xu R, Cheng XB, et al. Rational design of two-dimensional nanomaterials for lithium-sulfur batteries. Energy Environ Sci, 2020, 13: 1049-1075

5 Goodenough JB, Park KS. The Li-ion rechargeable battery: A perspective. J Am Chem Soc, 2013, 135: 1167-1176

6 Seh ZW, Sun Y, Zhang Q, et al. Designing high-energy lithiumsulfur batteries. Chem Soc Rev, 2016, 45: 5605-5634

7 Chung SH, Manthiram A. Current status and future prospects of metal-sulfur batteries. Adv Mater, 2019, 31: 1901125

8 Chung SH, Singhal R, Kalra V, et al. Porous carbon mat as an electrochemical testing platform for investigating the polysulfide retention of various cathode configurations in Li-S cells. J Phys Chem Lett, 2015, 6: 2163-2169

9 Fang X, Peng H. A revolution in electrodes: Recent progress in rechargeable lithium-sulfur batteries. Small, 2015, 11: 1488-1511

10 Fang R, Zhao S, Sun Z, et al. More reliable lithium-sulfur batteries: Status, solutions and prospects. Adv Mater, 2017, 29: 1606823

11 Yan M, Chen H, Yu Y, et al. 3D ferroconcrete-like aminated carbon nanotubes network anchoring sulfur for advanced lithiumsulfur battery. Adv Energy Mater, 2018, 8: 1801066

12 Yang J, Xie J, Zhou X, et al. Functionalized N-doped porous carbon nanofiber webs for a lithium-sulfur battery with high capacity and rate performance. J Phys Chem C, 2014, 118: 1800-1807

13 Zeng SZ, Yao Y, Zeng X, et al. A composite of hollow carbon nanospheres and sulfur-rich polymers for lithium-sulfur batteries. J Power Sources, 2017, 357: 11-18

14 Zhou G, Pei S, Li L, et al. A graphene-pure-sulfur sandwich structure for ultrafast, long-life lithium-sulfur batteries. Adv Mater, 2014, 26: 625-631

15 Tang C, Li BQ, Zhang Q, et al. CaO-templated growth of hierarchical porous graphene for high-power lithium-sulfur battery applications. Adv Funct Mater, 2016, 26: 577-585

16 Wang DW, Zeng Q, Zhou G, et al. Carbon-sulfur composites for Li-S batteries: Status and prospects. J Mater Chem A, 2013, 1: 9382

17 Hong YJ, Lee JK, Chan Kang Y. Yolk-shell carbon microspheres with controlled yolk and void volumes and shell thickness and their application as a cathode material for Li-S batteries. J Mater Chem A, 2017, 5: 988-995

18 Chen KS, Balla I, Luu NS, et al. Emerging opportunities for twodimensional materials in lithium-ion batteries. ACS Energy Lett, 2017, 2: 2026-2034

19 Jin J, Wu L, Huang S, et al. Hierarchy design in metal oxides as anodes for advanced lithium-ion batteries. Small Methods, 2018, 2: 1800171

20 Shao Q, Wu ZS, Chen J. Two-dimensional materials for advanced Li-S batteries. Energy Storage Mater, 2019, 22: 284-310

21 Pei F, Lin L, Ou D, et al. Self-supporting sulfur cathodes enabled by two-dimensional carbon yolk-shell nanosheets for high-energydensity lithium-sulfur batteries. Nat Commun, 2017, 8: 482

22 Feng $\mathrm{T}$, Zhang D, Li X, et al. $\mathrm{SnS}_{2}$ nanosheets for Er-doped fiber lasers. ACS Appl Nano Mater, 2019, 3: 674-681

23 Huang X, Putzke C, Guo C, et al. Magnetic electron collimation in three-dimensional semi-metals. npj Quantum Mater, 2020, 5: 12

24 Sanchez C. Hierarchy: Enhancing performances beyond limits. Natl Sci Rev, 2020, 7: 1624-1625

25 Su BL, Zhao D. Hierarchy: From nature to artificial. Natl Sci Rev, 2020, 7: 1623

26 Kim S, Lee J. Spinodal decomposition: A new approach to hierarchically porous inorganic materials for energy storage. Natl Sci 
Rev, 2019, 7: 1635-1637

27 Chen LH, Li Y, Su BL. Hierarchy in materials for maximized efficiency. Natl Sci Rev, 2020, 7: 1626-1630

$28 \mathrm{Wu} \mathrm{L}, \mathrm{Li}$ Y, Fu Z, et al. Hierarchically structured porous materials: Synthesis strategies and applications in energy storage. Natl Sci Rev, 2020, 7: 1667-1701

29 Peng HJ, Zhang Q. Designing host materials for sulfur cathodes: From physical confinement to surface chemistry. Angew Chem Int Ed, 2015, 54: 11018-11020

30 Zhang Q, Wang Y, Seh ZW, et al. Understanding the anchoring effect of two-dimensional layered materials for lithium-sulfur batteries. Nano Lett, 2015, 15: 3780-3786

31 Yan M, Zhang Y, Li Y, et al. Manganese dioxide nanosheet functionalized sulfur@PEDOT core-shell nanospheres for advanced lithium-sulfur batteries. J Mater Chem A, 2016, 4: 9403-9412

32 Zhang $\mathrm{Y}$, Liu X, Wu L, et al. A flexible, hierarchically porous $\mathrm{PANI} / \mathrm{MnO}_{2}$ network with fast channels and an extraordinary chemical process for stable fast-charging lithium-sulfur batteries. J Mater Chem A, 2020, 8: 2741-2751

33 Zhang W, Tian $\mathrm{Y}, \mathrm{He} \mathrm{H}$, et al. Recent advances in the synthesis of hierarchically mesoporous $\mathrm{TiO}_{2}$ materials for energy and environmental applications. Natl Sci Rev, 2020, 7: 1702-1725

34 Li Z, Deng S, Xu R, et al. Combination of nitrogen-doped graphene with $\mathrm{MoS}_{2}$ nanoclusters for improved Li-S battery cathode: Synthetic effect between 2D components. Electrochim Acta, 2017, 252: 200-207

35 Li X, Chu L, Wang Y, et al. Anchoring function for polysulfide ions of ultrasmall $\mathrm{SnS}_{2}$ in hollow carbon nanospheres for high performance lithium-sulfur batteries. Mater Sci Eng-B, 2016, 205: 46-54

36 Chen H, Dong WD, Xia FJ, et al. Hollow nitrogen-doped carbon/ sulfur@ $\mathrm{MnO}_{2}$ nanocomposite with structural and chemical dualencapsulation for lithium-sulfur battery. Chem Eng J, 2020, 381: 122746

37 Li X, Lu Y, Hou Z, et al. $\mathrm{SnS}_{2}$ - compared to $\mathrm{SnO}_{2}$-stabilized S/C composites toward high-performance lithium sulfur batteries. ACS Appl Mater Interfaces, 2016, 8: 19550-19557

38 Balach J, Linnemann J, Jaumann T, et al. Metal-based nanostructured materials for advanced lithium-sulfur batteries. J Mater Chem A, 2018, 6: 23127-23168

39 Liu D, Zhang C, Zhou G, et al. Catalytic effects in lithium-sulfur batteries: Promoted sulfur transformation and reduced shuttle effect. Adv Sci, 2018, 5: 1700270

40 Gao X, Yang X, Li M, et al. Cobalt-doped $\mathrm{SnS}_{2}$ with dual active centers of synergistic absorption-catalysis effect for high-S loading Li-S batteries. Adv Funct Mater, 2019, 29: 1806724

41 Hao J, Zhang D, Sun Q, et al. Hierarchical $\mathrm{SnS}_{2} / \mathrm{SnO}_{2}$ nanoheterojunctions with increased active-sites and charge transfer for ultrasensitive $\mathrm{NO}_{2}$ detection. Nanoscale, 2018, 10: 7210-7217

42 Yuan S, Fan C, Tian H, et al. Enhanced photoresponse of indiumdoped tin disulfide nanosheets. ACS Appl Mater Interfaces, 2020, 12: $2607-2614$

43 Jiang Y, Guo Y, Lu W, et al. Rationally incorporated $\mathrm{MoS}_{2} / \mathrm{SnS}_{2}$ nanoparticles on graphene sheets for lithium-ion and sodium-ion batteries. ACS Appl Mater Interfaces, 2017, 9: 27697-27706

44 Luo L, Chung SH, Manthiram A. A three-dimensional selfassembled $\mathrm{SnS}_{2}$-nano-dots@graphene hybrid aerogel as an efficient polysulfide reservoir for high-performance lithium-sulfur batteries. J Mater Chem A, 2018, 6: 7659-7667

45 Chen XY, Chen C, Zhang ZJ, et al. A general approach for producing nanoporous carbon, especially as evidenced for the case of adipic acid and zinc. J Mater Chem A, 2013, 1: 14919

46 Meng L, Yao Y, Liu J, et al. $\mathrm{MoSe}_{2}$ nanosheets as a functional host for lithium-sulfur batteries. J Energy Chem, 2020, 47: 241-247

47 Zhang Y, Zhu P, Huang L, et al. Few-layered $\mathrm{SnS}_{2}$ on few-layered reduced graphene oxide as $\mathrm{N}$-ion battery anode with ultralong cycle life and superior rate capability. Adv Funct Mater, 2015, 25: 481-489

48 Jiang $\mathrm{S}$, Chen $\mathrm{M}$, Wang $\mathrm{X}$, et al. A tin disulfide nanosheet wrapped with interconnected carbon nanotube networks for application of lithium sulfur batteries. Electrochim Acta, 2019, 313: 151-160

49 Li M, Zhou J, Zhou J, et al. Ultrathin $\mathrm{SnS}_{2}$ nanosheets as robust polysulfides immobilizers for high performance lithium-sulfur batteries. Mater Res Bull, 2017, 96: 509-515

50 Fan L, Li X, Song X, et al. Promising dual-doped graphene aerogel/ $\mathrm{SnS}_{2}$ nanocrystal building high performance sodium ion batteries. ACS Appl Mater Interfaces, 2018, 10: 2637-2648

51 Cai Y, Wang HE, Huang SZ, et al. Porous $\mathrm{TiO}_{2}$ urchins for high performance Li-ion battery electrode: Facile synthesis, characterization and structural evolution. Electrochim Acta, 2016, 210: 206214

$52 \mathrm{Wu}$ J, Chen B, Liu QQ, et al. Preparing a composite including $\mathrm{SnS}_{2}$, carbon nanotubes and $\mathrm{S}$ and using as cathode material of lithiumsulfur battery. Scripta Mater, 2020, 177: 208-213

53 Liu Q, Jiang Q, Jiang L, et al. Preparation of $\mathrm{SnO}_{2} @ \mathrm{rGO} / \mathrm{CNTs} / \mathrm{S}$ composite and application for lithium-sulfur battery cathode material. Appl Surf Sci, 2018, 462: 393-398

54 Wei W, Li J, Wang Q, et al. Hierarchically porous $\mathrm{SnO}_{2}$ nanoparticle-anchored polypyrrole nanotubes as a high-efficient sulfur/ polysulfide trap for high-performance lithium-sulfur batteries. ACS Appl Mater Interfaces, 2020, 12: 6362-6370

55 Wang $\mathrm{M}$, Fan L, Wu X, et al. Hierarchical mesoporous $\mathrm{SnO}_{2}$ nanosheets on carbon cloth toward enhancing the polysulfides redox for lithium-sulfur batteries. J Mater Chem A, 2017, 5: 19613-19618

56 Li X, Guo G, Qin N, et al. $\mathrm{SnS}_{2} / \mathrm{TiO}_{2}$ nanohybrids chemically bonded on nitrogen-doped graphene for lithium-sulfur batteries: Synergy of vacancy defects and heterostructures. Nanoscale, 2018, 10: $15505-15512$

57 Yao S, Zhang C, Xie F, et al. Hybrid membrane with $\mathrm{SnS}_{2}$ nanoplates decorated nitrogen-doped carbon nanofibers as binder-free electrodes with ultrahigh sulfur loading for lithium sulfur batteries. ACS Sustain Chem Eng, 2020, 8: 2707-2715

58 Cao B, Li D, Hou B, et al. Synthesis of double-shell $\mathrm{SnO}_{2} @ \mathrm{C}$ hollow nanospheres as sulfur/sulfide cages for lithium-sulfur batteries. ACS Appl Mater Interfaces, 2016, 8: 27795-27802

59 Shao Q, Guo D, Wang C, et al. Yolk-shell structure $\mathrm{MnO}_{2} @$ hollow carbon nanospheres as sulfur host with synergistic encapsulation of polysulfides for improved Li-S batteries. J Alloys Compd, 2020, 842: 155790

60 Zhou G, Tian H, Jin Y, et al. Catalytic oxidation of $\mathrm{Li}_{2} \mathrm{~S}$ on the surface of metal sulfides for Li-S batteries. Proc Natl Acad Sci USA, 2017, 114: 840-845

61 Choi HU, Jin JS, Park JY, et al. Performance improvement of allsolid-state Li-S batteries with optimizing morphology and structure of sulfur composite electrode. J Alloys Compd, 2017, 723: 787-794

62 Qin $\mathrm{H}$, Chen $\mathrm{L}$, Wang $\mathrm{L}$, et al. $\mathrm{V}_{2} \mathrm{O}_{5}$ hollow spheres as high rate and long life cathode for aqueous rechargeable zinc ion batteries. Electrochim Acta, 2019, 306: 307-316

63 Lim WG, Jo C, Cho A, et al. Approaching ultrastable high-rate Li-S batteries through hierarchically porous titanium nitride synthe- 
sized by multiscale phase separation. Adv Mater, 2019, 31: 1806547 64 Dong W, Chen H, Xia F, et al. Selenium clusters in Zn-glutamate MOF derived nitrogen-doped hierarchically radial-structured microporous carbon for advanced rechargeable Na-Se batteries. J Mater Chem A, 2018, 6: 22790-22797

Acknowledgements This work was supported by the National Key R\&D Program of China (2016YFA0202602), the National Natural Science Foundation of China (U1663225), the Fundamental Research Funds for the Central Universities (2020-YB-009), the Academy of Scientific Research and Technology (6611, ASRT, Egypt), the $111 \mathrm{Na}$ tional project (B20002) from the Ministry of Science and Technology and the Ministry of Education, China and Sinopec Ministry of Science and Technology Basic Prospective Research Project (217027-5 and 218025-9).

Author contributions $\mathrm{Li}$ Y and Su BL conceived the idea of this work. Zhou N, Dong WD, Zhang YJ, Wang D, and Mohamed HSH carried out the materials synthesis and characterized the performances of materials. $\mathrm{Wu} \mathrm{L}$ and Liu J performed the SEM observations. Wang L and Hu ZY carried out the TEM observations. Dong WD performed the DFT calculation. Zhou N and Li Y wrote the manuscript. Li Y, Chen LH, and Su $\mathrm{BL}$ together discussed and revised the manuscript. Li Y supervised the project.

Conflict of interest The authors declare that they have no conflict of interest.

Supplementary information Supporting data are available in the online version of the paper.

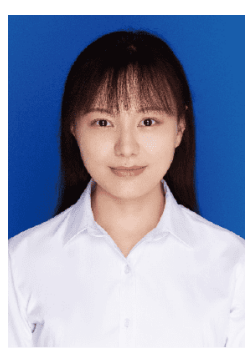

Na Zhou is a MSc candidate under the supervision of Prof. Dr. Bao-Lian Su and Prof. Dr. Yu $\mathrm{Li}$ at the State Key Laboratory of Advanced Technology for Materials Synthesis and Processing, Wuhan University of Technology. Her research direction is the design of hierarchically porous materials for Li-S batteries.

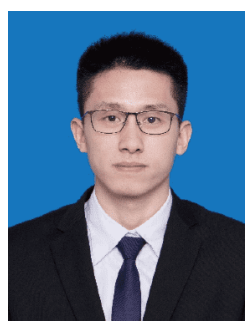

Wen-Da Dong received his MSc degree from the State Key Laboratory of Advanced Technology for Materials Synthesis and Processing, Wuhan University of Technology. He is currently a $\mathrm{PhD}$ candidate and his research focuses on the design of micro/nano-composite materials for Li-Se and Na-Se batteries.

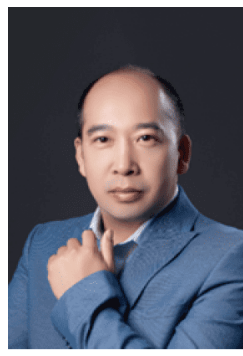

Yu Li received his BSc degree from Xi'an Jiaotong University in 1999 and his MSc from Liaoning Shihua University in 2002. He obtained his $\mathrm{PhD}$ from Zhejiang University in 2005 . He worked in electron microscopy for materials science (EMAT) at the University of Antwerp with Prof. G. Vantendeloo in 2005 and then in the Laboratory of Inorganic Materials Chemistry (CMI) at the University of Namur with Prof. Bao-Lian Su in 2006. Currently, he is a full-time professor at Wuhan University of Technology. His research interests include nanomaterials design and synthesis, hierarchically porous materials synthesis, and their applications in the fundamental aspects of energy and environment.

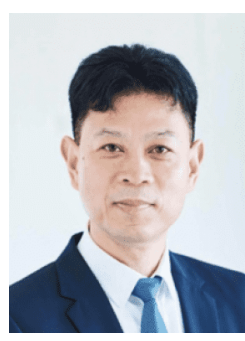

Bao-Lian Su created the CMI at the University of Namur, Belgium in 1995. He is currently a full professor of chemistry, member of the Royal Academy of Belgium, fellow of the Royal of Society of Chemistry, UK and Life Member of Clare Hall College and University of Cambridge. He is also Cheung Kong Professor and a strategy scientist at Wuhan University of Technology, China. His current research fields include the synthesis, the property study and the molecular engineering of organized, hierarchically porous and bio-organisms for artificial photosynthesis, (photo) catalysis, energy conversion and storage, biotechnology, cell therapy and biomedical applications.

\section{二硫化锡纳米颗粒嵌入二维多孔碳纳米片中间层} 用于快充理硫电池

周娜 ${ }^{1 \dagger}$, 董文达 ${ }^{1 \dagger}$, 张云静 ${ }^{1}$, 王迪 ${ }^{1}$, 吴亮 ${ }^{1}$, 王浪 ${ }^{1,2}$, 胡执一 ${ }^{1,2}$ 刘婧 ${ }^{1}$, Hemdan S. H. Mohamed ${ }^{1,3}$, 李昱 ${ }^{1,2^{*}}$, 陈丽华 ${ }^{1}$, 苏宝连 $14^{*}$

摘要 本文报道了将小尺寸二硫化锡 $\left(\mathrm{SnS}_{2}\right)$ 纳米颗粒嵌入到二维多 孔碳纳米片 $(\mathrm{PCN})$ 中间层, 形成多功能纳米复合材料 $\left(\mathrm{PCN}-\mathrm{SnS}_{2}\right)$ 作 为硫正极载体, 从而降低穿梭效应, 实现锂硫电池快充. 一方面, 复 合材料中石墨化碳纳米片可整体性提高电极的导电性. 另一方面, 复合材料丰富的孔道既促进离子转移和电解质的渗透, 又缓解充 放电过程中的体积变化, 从而确保电极材料的完整性. 特别地, $\mathrm{PCN}$ 的物理限域和小尺寸 $\mathrm{SnS}_{2}$ 纳米颗粒的强化学吸附协同作用可 有效降低多硫化物的穿梭效应. 因此, PCN-SnS 2 -S电极具有良好的 电化学性能, 即使在 $2 \mathrm{C}$ 的高电流密度下, 150 圈循环后仍可维持 $650 \mathrm{~mA} \mathrm{~h} \mathrm{~g}{ }^{-1}$ 的放电容量. 本研究工作为小尺寸 $\mathrm{SnS}_{2}$ 纳米结构更利 于捕获多硫化物以减弱锂硫电池的穿梭效应提供了理论基础. 